Supporting Information

\title{
A Highly Active Biohybrid Catalyst for Olefin Metathesis in Water: Impact of a Hydrophobic Cavity in a $\beta$-Barrel Protein
}

Daniel F. Sauer, ${ }^{\dagger}$ Tomoki Himiyama, ${ }^{\ddagger}$ Kengo Tachikawa, ${ }^{\ddagger}$ Kazuki Fukumoto, ${ }^{\ddagger}$ Akira Onoda, ${ }^{\ddagger}$ Eiichi Mizohata, ${ }^{\ddagger}$ Tsuyoshi Inoue, ${ }^{\ddagger}$ Marco Bocola, ${ }^{\S}$ Ulrich Schwaneberg, ${ }^{\S}$ Takashi Hayashi, ${ }^{\ddagger}, *$ Jun Okuda*,†

†Institute of Inorganic Chemistry, RWTH Aachen University, Landoltweg 1, 52056 Aachen, Germany $\ddagger$ Department of Applied Chemistry, Graduate School of engineering, Osaka University, 2-1 Yamadaoka, Suita 565-0871, Japan

§ Institute of Biotechnology, RWTH Aachen University, Worringer Weg 1, 52056 Aachen, Germany

e-mail: jun.okuda@ac.rwth-aachen.de 


\section{Table of Contents}

\begin{tabular}{ll} 
General Comments $\quad$ S3 \\
\hline
\end{tabular}

Conjugation of the Grubbs-Hoveyda Type Complexes S3

General Procedure for ROMP of Oxanorbornene Derivative $3 \quad$ S4

General Procedure for RCM of Diol 1

UV/VIS Spectroscopy

$\begin{array}{ll}\text { MALDI-TOF MS } & \text { S7 }\end{array}$

$\begin{array}{ll}\text { ESI-TOF MS S8 } & \text { S8 }\end{array}$

$\begin{array}{ll}\text { CD Spectroscopy } & \text { S9 }\end{array}$

$\begin{array}{ll}\text { X Ray Structure Analysis } & \text { S11 }\end{array}$

$\begin{array}{ll}\text { Molecular Modeling } & \text { S12 }\end{array}$

$\begin{array}{ll}\text { Size Exclusion Chromatography } & \text { S17 }\end{array}$

$\begin{array}{ll}\text { References } & \text { S18 }\end{array}$ 


\section{General Comments}

All experiments were performed under a nitrogen or argon atmosphere using standard Schlenk techniques or an MBraun nitrogen-filled glovebox. DMSO was degassed by using "pumpfreeze-thaw" cycles. ${ }^{1} \mathrm{H}-\mathrm{NMR}$ spectra were recorded on a Bruker DPX400 NMR spectrometer. Chemical shifts are reported in ppm relative to the residual solvent resonances. MALDI-TOF MS analyses were performed on a Bruker autoflex III mass spectrometer. ESI-TOF MS analysis was performed on a Bruker microTOF focus III spectrometer. UV/VIS spectra were recorded on a Shimadzu BioSpec-nano. Circular dichroism (CD) spectra were recorded on a JASCO J720S spectrometer. The pH values were measured with a Horiba F52 pH meter. Gel permeation chromatography (GPC) was performed on a TOSOH SC8020 apparatus with a refractive index (RI) detector with a TOSOH TSKGel G5000H HR column. Gas chromatography (GC) was performed on a Shimadzu GC-2014. Size Exclusion Chromatography (SEC) was performed with GE Healthcare Sephadex G-25 medium. Inductively Coupled Plasma Atomic Emission Spectroscopy (ICP-AES) measurements were performed on a Shimadzu ICPS-7510. A serial dilution was prepared by using a commercially available ruthenium standard $(0.992 \mu \mathrm{g} / \mathrm{mL}$; Fluka Analytical, Sigma-Aldrich catalog number: 207446-100ML). The calibration was done with samples containing $0.0 \mu \mathrm{M}, 0.5 \mu \mathrm{M}, 1 \mu \mathrm{M}$ and $2 \mu \mathrm{M} \mathrm{Ru}$. The protein sample was diluted to $1.5 \mu \mathrm{M}$ protein concentrations. Each batch biohybrid conjugate was analyzed prior to use in catalysis. Grubbs-Hoveyda type complexes $\mathbf{C O H},{ }^{1} \mathbf{C 1 - 3},{ }^{1-2}$ Substrates $\mathbf{1}^{3}$ and $\mathbf{3}^{4}$ were synthesized as previously reported. Nitrobindin variants were obtained by the protocol reported recently. ${ }^{5}$

Conjugation of the Grubbs-Hoveyda Type Complexes. To a solution containing the nitrobindin variant $(10 \mu \mathrm{M})$ freshly reduced with DTT in Tris-HCl buffer $(10 \mu \mathrm{M}, \mathrm{pH} 7.5,50$ $\mu \mathrm{M} \mathrm{NaCl}$ ), complex C3 (10 equiv) in DMSO (1\% (v/v)) was added. Complex C1 or C2 (10 equiv respectively) were added in $10 \%(\mathrm{v} / \mathrm{v})$ DMSO. After $1 \mathrm{~h}$, the reaction mixture was centrifuged to remove precipitates, the supernatant was concentrated (ca. $1 \mathrm{~mL}$ ) by using an amicon ultrafiltration cell (10 kDa MWCO). If more than $1 \%(\mathrm{v} / \mathrm{v})$ DMSO was used, the solution was diluted to $5 \mathrm{~mL}$ and concentrated again $(2 \mathrm{x})$. The proteins were purified on a sephadex column (GE Healthcare) with Tris-HCl buffer (pH 7.5, $10 \mathrm{mM}, 200 \mathrm{mM} \mathrm{NaCl}$ ) as an eluent.

Trace metal analysis of the washing solution of a blank run with protein $(10 \mu \mathrm{M}, \mathrm{pH} 7.5,50$ $\mu \mathrm{M} \mathrm{NaCl}$ ) and $\mathbf{C O H}$ (10 equiv) in DMSO (1\% (v/v)) showed no detectable Ru after purification.

The coupling efficiencies are calculated by the protein concentration determined by the absorption at $280 \mathrm{~nm}$ and the Ru content determined by ICP-AES; NB4_C3: 25\%; NB11_C1: 29\%; NB11_C2: 50\%; NB11_C3: 89\%. 
<smiles>CC(C)Oc1ccccc1/C=[R](/[C@@H]1N(C)CC(CO)N1S(C)(=O)=O)C(Cl)(Cl)Cl</smiles>

$\mathrm{COH}$

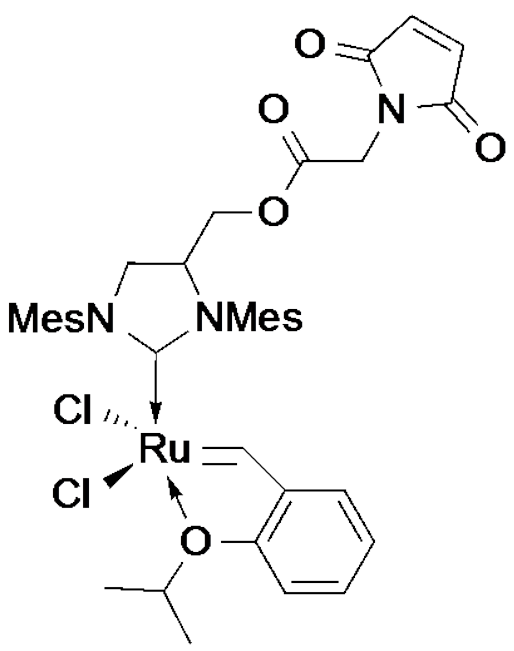

C1

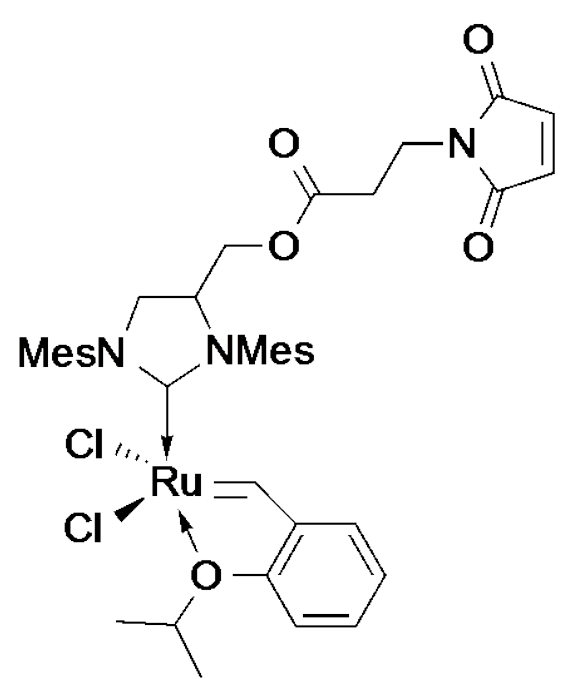

C2

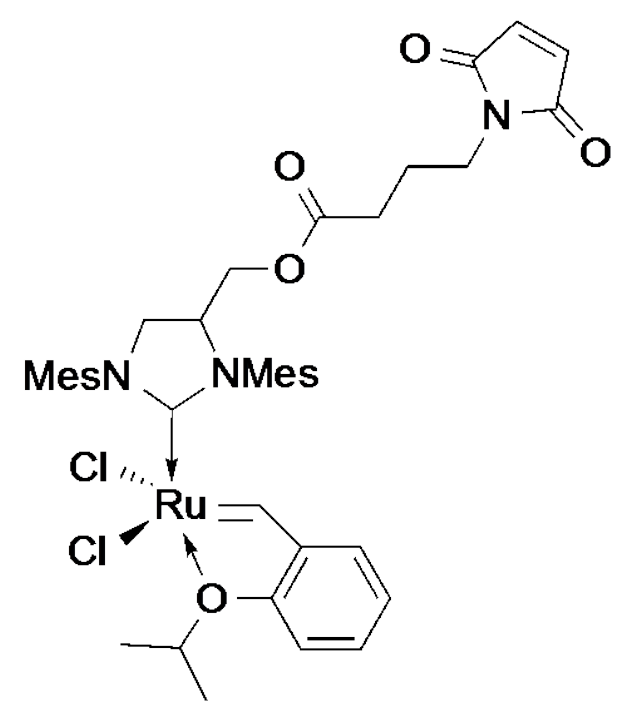

C3

Figure S1. Grubbs-Hoveyda type catalyst used in this study.

General procedure for ROMP of oxanorbornene derivative 3. The freshly prepared and filtered biohybrid catalyst ( $500 \mu \mathrm{L}$ of a $16 \mu \mathrm{M}$ solution, based on the ruthenium content as determined by ICP-AES) was subjected to a HiTrap desalting column to exchange the buffer to either Tris-HCl buffer solution ( $\mathrm{pH} 7.5,10 \mathrm{mM}, 200 \mathrm{mM} \mathrm{NaCl}$ ) or in MES buffer solution (5 $\mathrm{mM}$, pH 6.0, $200 \mathrm{mM} \mathrm{NaCl})$. Oxanorbornen derivative 3 was added via syringe (15 $\mu \mathrm{L}, 0.2 \mathrm{M})$ to the solution containing the biohybrid catalysts. After reaction time of $12 \mathrm{~h}$ or $24 \mathrm{~h}, 0.5 \mathrm{~mL}$ of THF and $0.5 \mathrm{~mL}$ of ethylvinylether were added and the solution was mixed on a vortex and incubated at room temperature for $20 \mathrm{~min}$. The substrate and polymer was extracted with chloroform, the organic phase was filtered, dried over $\mathrm{MgSO}_{4}$, and analyzed by ${ }^{1} \mathrm{H} \mathrm{NMR}$ spectroscopy in $\mathrm{CDCl}_{3}$. The conversion and the cis/trans ratio was determined by the method reported by Feast and Harrision. ${ }^{3}$ 
General procedure for RCM of diol 1. The freshly prepared and filtered biohybrid catalyst (1 $\mathrm{mL}$ of a $1.25 \mathrm{mM}$ solution, based on the ruthenium content as determined by ICP-AES) was subjected to a HiTrap desalting column to exchange the buffer to MES buffer solution ( $\mathrm{pH}$ 6.0, $5 \mathrm{mM}, 200 \mathrm{mM} \mathrm{NaCl}$ ). Diol 1 was added via syringe (19.5 mg, $125 \mathrm{mmol}$ ) and the reaction mixture was heated to $40{ }^{\circ} \mathrm{C}$. After reaction time of $24 \mathrm{~h} 0.5 \mathrm{~mL}$ THF and $0.5 \mathrm{~mL}$ ethylvinylether were added and the solution was mixed on a vortex and incubated at room temperature for $20 \mathrm{~min}$. The substrate and the product were extracted with chloroform, the organic phase was filtered, dried over $\mathrm{MgSO}_{4}$, and analyzed by ${ }^{1} \mathrm{H}$ NMR spectroscopy and GC.

RCM was carried out with 4,4-bis(hydroxymethyl)-1,6-heptadiene 1 as water-soluble substrate. The advantage is that it is not denaturing the protein structure. The reactions were performed in the acidic buffer and with slightly higher temperatures (Table 1). With a catalyst loading of 1 mol \% with catalyst NB11_C2, a conversion of 89\% can be achieved, and for catalyst NB11_C3 full conversion is reached within $24 \mathrm{~h}$. Compared to the other literature known biohybrid metathesis catalysts the activity is much higher under comparable conditions. The substrate accessibility and stability of the $\beta$-barrel structure makes this system potentially useful in metathesis reactions in water. 


\section{UV/VIS Spectroscopy}
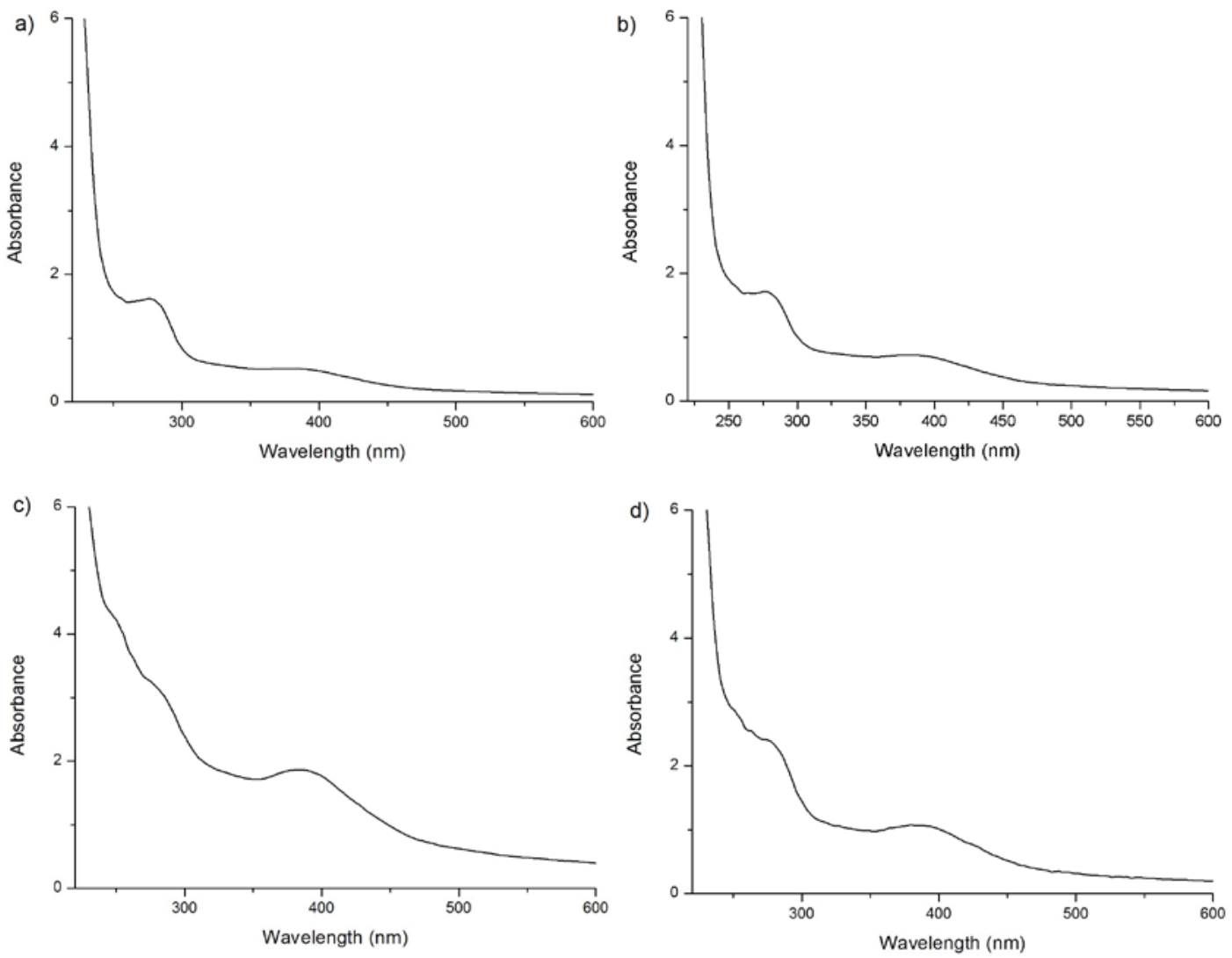

Figure S2. UV/VIS spectra. a) NB11_C1; b) NB11_C2; c) NB11_C3; d) NB4_C3. 


\section{MALDI-TOF MS}

a)

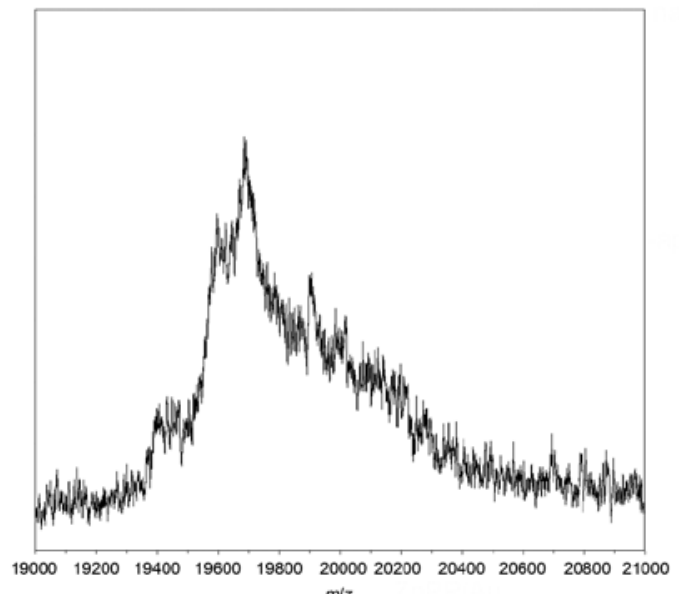

c)

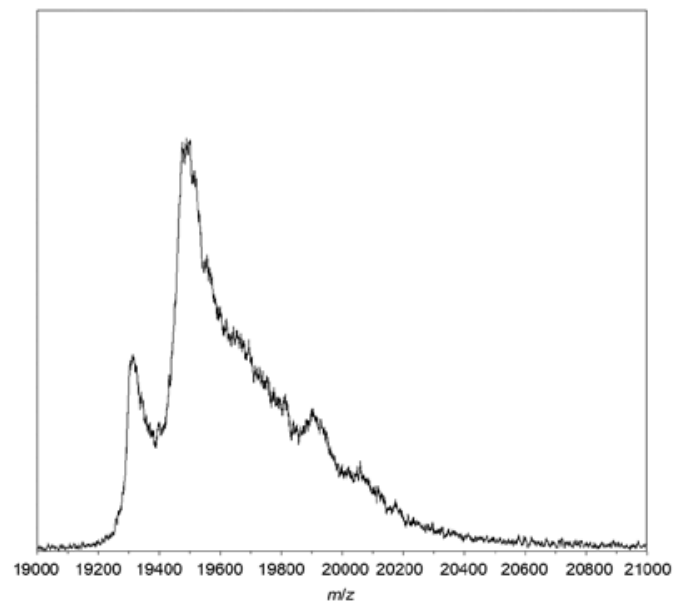

b)

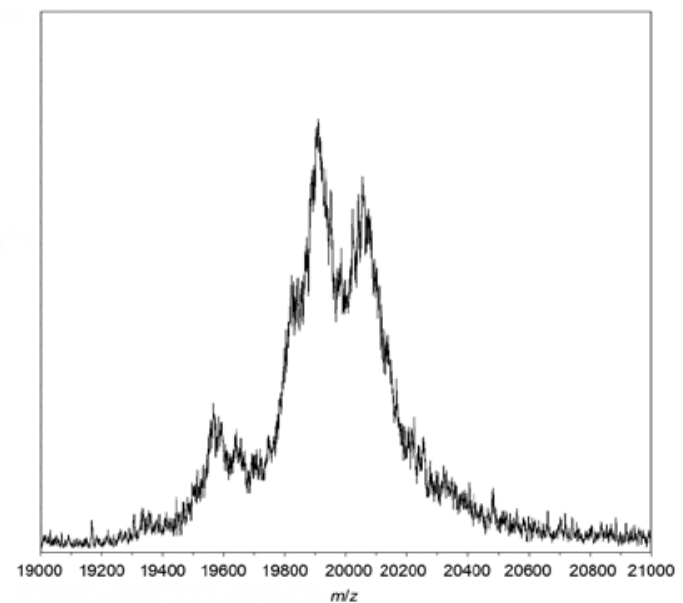

d)

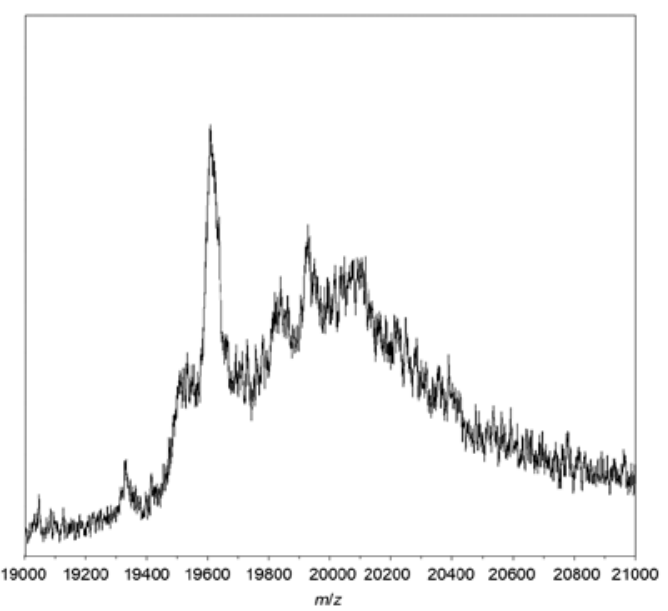

Figure S3. MALDI-TOF MS spectra of a) NB4_C3 (20238.71), b) NB11_C1 (20126.19), c) NB11_C2 (calcd. 20154.55), and d) NB11_C3 (20154.55). Calculated mass of the apo forms: NB4: 19416.92; NB11: 19332.76. The broad peak distribution occurs because of reaction of the catalyst with sinapinic acid used as a matrix. 


\section{ESI-TOF MS}

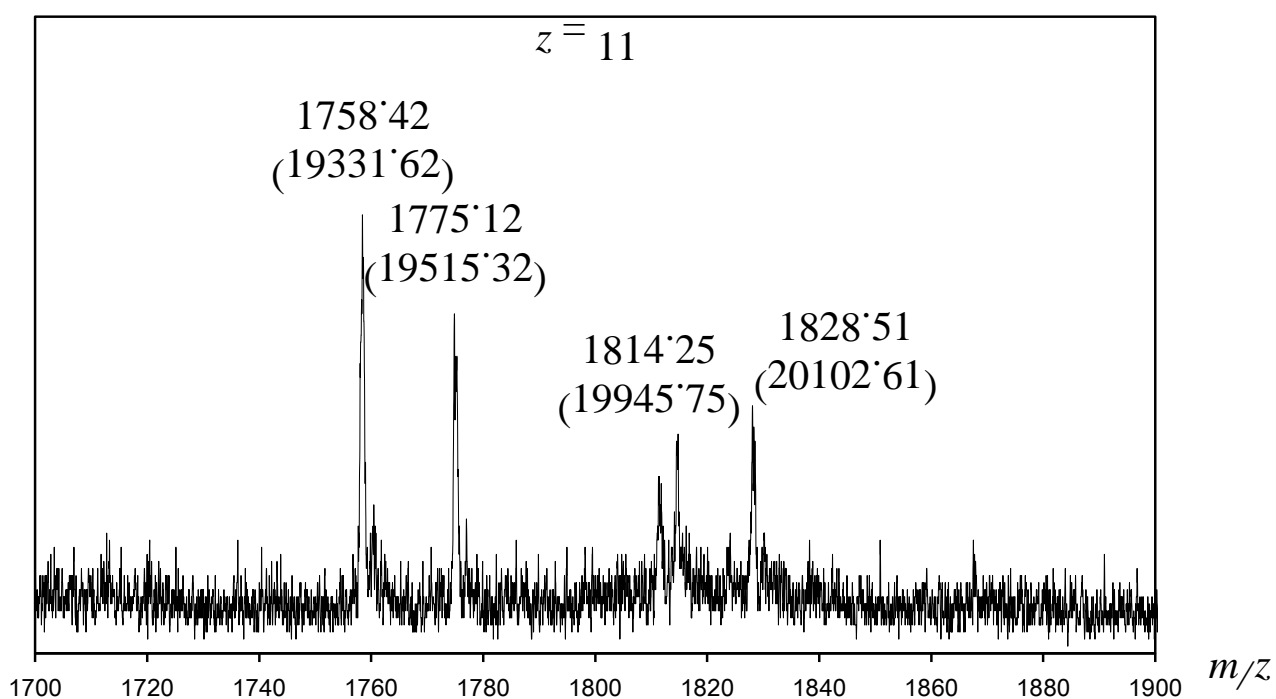

Figure S4. ESI-TOF MS spectrum of NB11_C3 (10 mM in 20 mM ammonium acetate buffer). Apo NB11: 19331.6 (calculated: 19332.8); NB11 + $\mathrm{C}_{8} \mathrm{H}_{9} \mathrm{NO}_{4}$ : 19515.3 (ester cleavage; calculated: 19515.8); NB11 + GHOH -Cl: 19945.7 (catalyst fragment of ester cleavage + NB11; calculated: 19952.4); NB11_C3 -2CI +H2O: 20102.6 (calculated: 20102.0). 


\section{Spectroscopy}
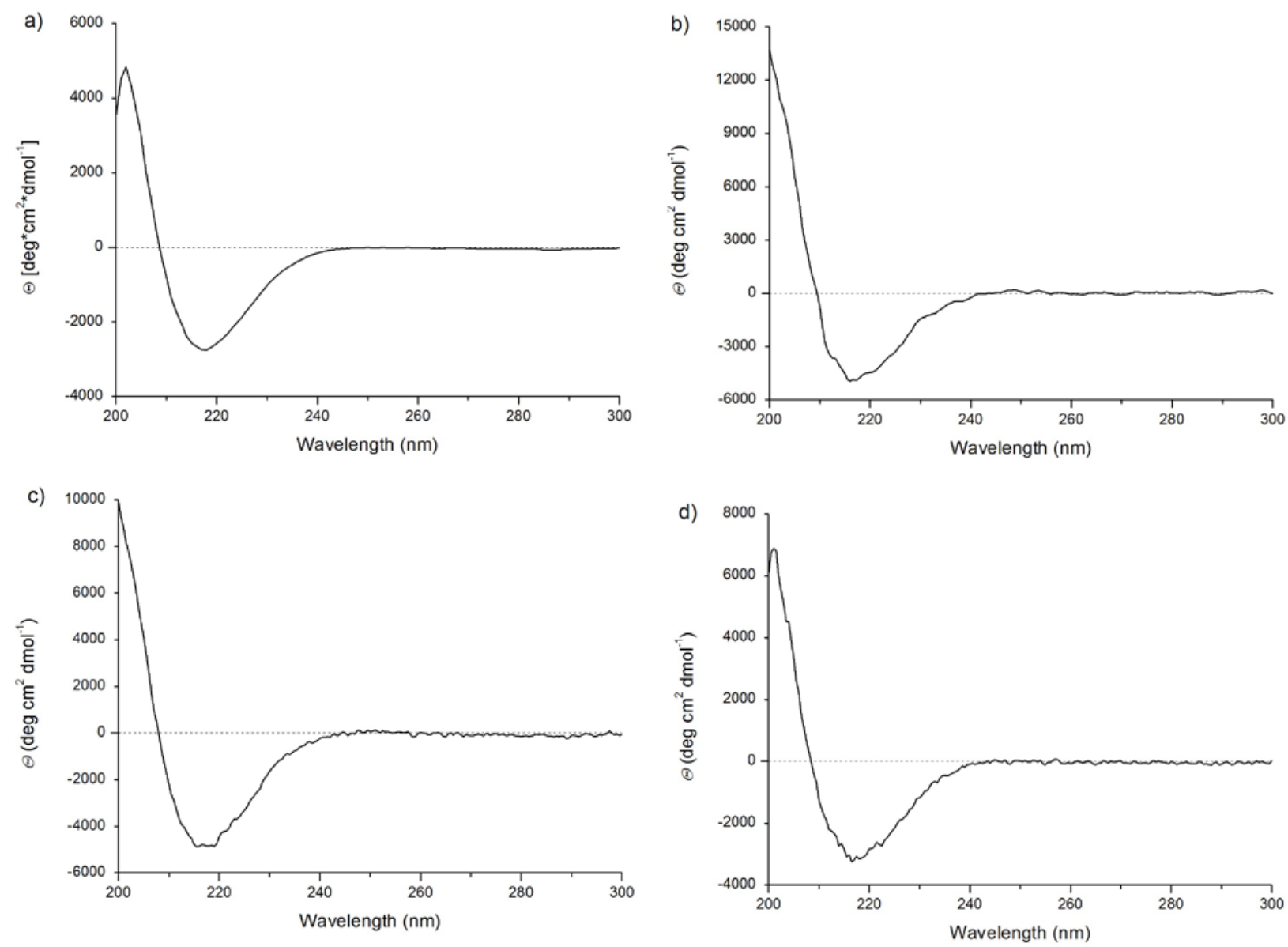

Figure S5. CD spectra of a) NB11_C1, b) NB11_C2, c) NB11_C3, and d) NB4_C3 in TrisHCl buffer (pH 7.5, 10 mM, 200 mM NaCl). 


\section{X-Ray Crystallography}

NB11 crystals were prepared by the hanging-drop vapor diffusion method at $293 \mathrm{~K}$. The crystals were grown on siliconized coverslips by equilibrating a mixture containing $1.0 \mu \mathrm{L}$ of the protein solution $(1.0 \mathrm{mM}$ protein in $5 \mathrm{mM}$ MES buffer, $\mathrm{pH} 6.0,200 \mathrm{mM} \mathrm{NaCl}, 1 \mathrm{mM}$ dithioerythritol) and $1.0 \mu \mathrm{L}$ of the reservoir solution $(100 \mathrm{mM}$ Tris-HCl buffer, $\mathrm{pH} 8.3$, $17 \%(\mathrm{w} / \mathrm{v})$ polyethylene glycol 2000) with $100 \mu \mathrm{L}$ of the reservoir solution.

The X-ray diffraction data were collected at SPring-8 BL44XU. A single crystal of NB11 was fished with standard nylon loop, soaked in cryoprotectant solution $(67 \%(\mathrm{v} / \mathrm{v})$ Paraton-N, 28\%(v/v) paraffin oil, 5\%(v/v) glycerol), and flash-cooled in an $\mathrm{N}_{2}$ gas stream at $100 \mathrm{~K}$. The data were integrated and scaled using the program $H K L 2000,{ }^{6}$ and further processed using the CCP4 software package. ${ }^{7}$ The initial phases were obtained by the molecular replacement method using the program PHASER. ${ }^{8}$ The reported structure of nitrobindin (PDB code 2A13) was used as a search model. The model was refined with multiple rounds of manual rebuilding using COOT, ${ }^{9}$ and crystallographic refinement by REFMAC5. ${ }^{10}$ The data collection and refinement statistics are summarized in Table S1. Figures depicting the structure were prepared with PYMOL (http://www.pymol.org). The atomic coordinates and structure factors were deposited into the Protein Data Bank (http://www.rcsb.org/ PDB codes: 4YMY). 
Table S1. Statistics of X-ray Crystallographic Data and Structure Refinement

\begin{tabular}{lc}
\hline \multicolumn{2}{c}{ Data collection } \\
\hline X-ray source & SPring-8 BL44XU \\
Detector & Rayonix MX300HE \\
Wavelength $(\AA)$ & 0.90000 \\
Resolution $(\AA)$ (outer shell) ${ }^{\text {a }}$ & $1.00(1.04-1.00)$ \\
Space group & $P 2{ }_{1} 2{ }_{1} 2$ \\
Unit cell parameters $(\AA)$ & $79.29, c=36.41$ \\
No. of total reflections & 945,036 \\
No. of unique reflections & 92,122 \\
Completeness $(\%)$ & $98.3(95.7)$ \\
$R_{\text {sym }}$ & $5.1(37.5)$ \\
$I / \sigma(I)$ & $42.7(4.2)$ \\
$R_{\text {sym }}(\%)$ & $5.1(37.5)$ \\
Completeness $(\%)^{a}$ & $98.3(95.7)$ \\
\hline
\end{tabular}

Refinement

\section{Resolution $(\AA)$}

No. of reflections

$R_{\text {cryst }} / R_{\text {free }}(\%)$

Mean $B$-factor $\left(\AA^{2}\right)$

No. of non-H atoms

Rmsd from ideal

Bond lengths $(\AA)$ / angles (deg.)
$47.67-1.00$

87,472

$12.3 / 13.6$

18.7

1,479

${ }^{a}$ Numbers in parentheses are for the highest-resolution shell.

${ }^{\mathrm{b}} R_{\text {sym }}=\Sigma_{h k l} \Sigma_{i}\left|I_{i}(h k l)-<I(h k l)>\right| / \Sigma_{h k l} \Sigma_{i} I_{i}(h k l)$ where $\langle I(h k l)>$ is the average intensity of the $i$ observations. $R=\sum_{h k l}\left|F_{\text {obs }}(h k l)-F_{\text {calc }}(h k l)\right| / \sum_{h k l} F_{\text {obs }}(h k l)$, where $F_{\text {obs }}$ and $F_{\text {calc }}$ are observed and calculated structure factors, respectively. $R$ free was calculated with $5 \%$ of the reflections. 


\section{Molecular Modeling}

Modeling of the apo-NB variants, NB4, NB11, was performed as reported previously ${ }^{5}$ using YASARA $^{11}$ Structure Vers. 13.6.16, employing force field AMBER03. ${ }^{12}$ The calculated structures were visualized in Figure S6-S11. Furthermore, the modeling of the hybrid biocatalyst was also performed. As structural basis for the modeling of the hybrid biocatalysts, the X-ray structure of native nitrobindin (PDB: 2A13), and the NB variants (NB4 (PDB: 3WJB) and 11 (PDB: 4YMY)) were used. According to the previously published procedure, ${ }^{5}$ the modeling was carried out using YASARA Structure Vers. 13.6.16 employing force field AMBER03 for protein residues and GAFF $^{13}$ using AM1/BCC ${ }^{14}$ partial charges for the catalyst covalently bound to Cys96. The metal was replaced by cobalt, since no parameters are available for ruthenium. To maintain the correct coordination geometry, the distances and angles from the metal to all coordinating atoms were constrained according to the X-ray structure of the Grubbs-Hoveyda catalyst ${ }^{15}$ by force field arrows. The charge of the metal was set to +2 and the total charge of the catalyst was set to zero. The linker was placed manually in the cavity adjacent to Cys96 and a bond from Cys S atom to the $\mathrm{C} 1$ atom of the maleimide group was defined, according to the linker geometry in the high resolution X-ray structure of the rhodium complex. The constructed hybrid catalysts were solvated in a box of TIP3P water molecules using periodic boundaries at $\mathrm{pH} 7$ and a density of $0.997 \mathrm{~g} / \mathrm{mL}$. Three starting structures were analyzed and favorable models were identified for covalent attachment to the reactive maleimide atoms by steepest descent minimization and simulated annealing. The preminimized structures were relaxed using molecular dynamics calculations at $298 \mathrm{~K}$ for $5000 \mathrm{ps}$ and snapshots were taken every 25 ps to analyze the binding modes. van der Waals volume of the ligand was calculated using Yasara and the MSMS program. ${ }^{16}$ Cavity size were calculated using the online server Pocket-finder based on the Ligsite algorithm written by Hendlich et al. ${ }^{17}$ 
Table S2. Selected distances and volumes of the catalysts and biohybrid catalysts.

\begin{tabular}{|c|c|c|c|c|}
\hline Entry & $\begin{array}{c}\text { Catalyst or } \\
\text { Protein }\end{array}$ & $\begin{array}{c}\text { Cavity Volume } \\
{\left[\AA^{3}\right]}\end{array}$ & $\begin{array}{c}\text { van der Waals } \\
\text { Volume }\left[\AA^{3}\right]\end{array}$ & Distance Cys C96-Ru [Å] \\
\hline 1 & C1 & - & 752 & - \\
\hline 2 & C2 & - & 768 & - \\
\hline 3 & C3 & - & 795 & - \\
\hline 4 & NB4 & 855 & - & - \\
\hline 5 & NB11 & 1161 & - & - \\
\hline 6 & NB11_C1 & - & - & 11.83 \\
\hline 7 & NB11_C2 & - & - & 12.56 \\
\hline 8 & NB11_C3 & - & - & 12.78 \\
\hline 9 & NB4_C3 & - & - & 13.75 \\
\hline
\end{tabular}



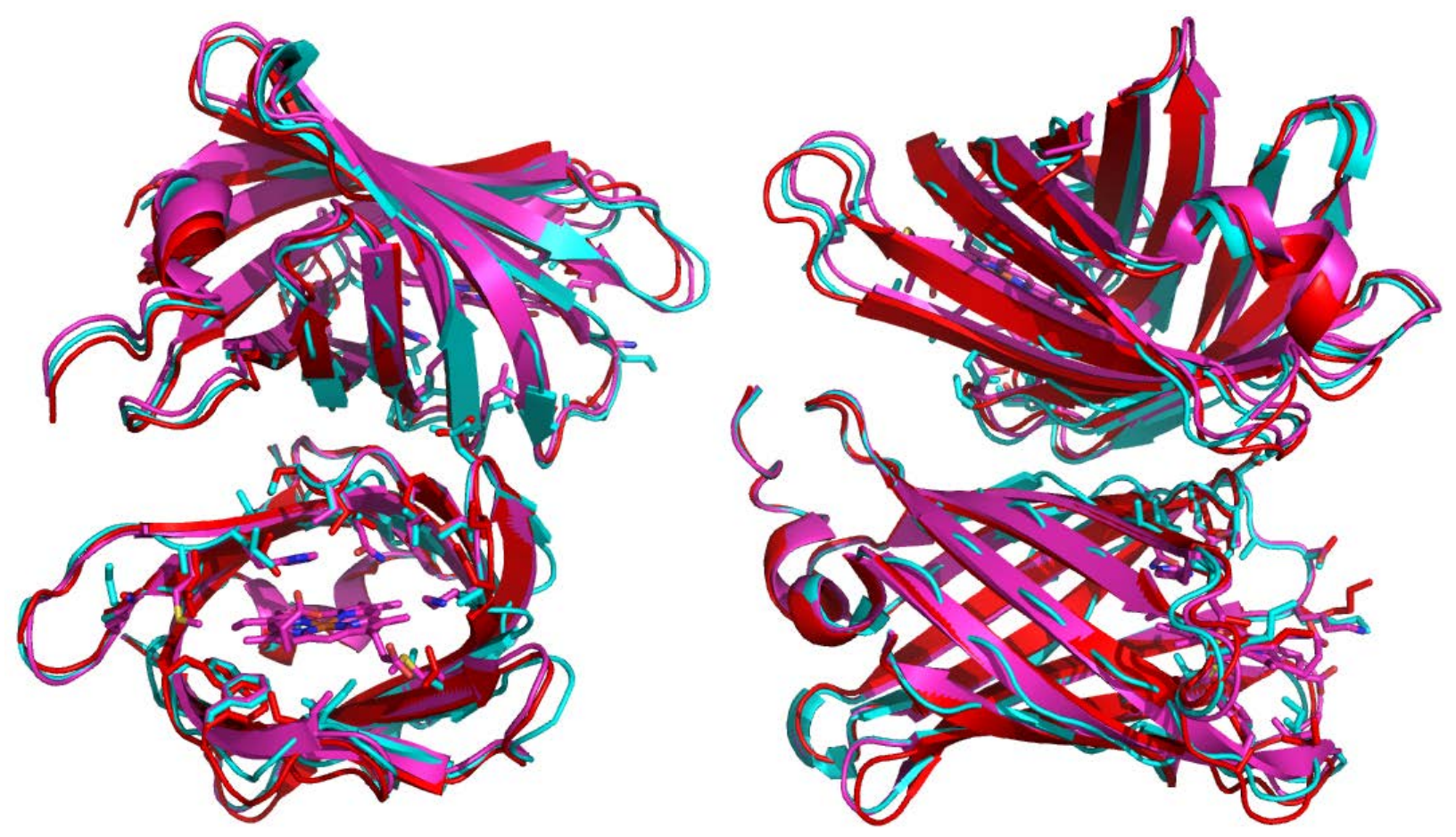

Figure S6. Overlay of the crystal structures of native nitrobindin containing the heme cofactor (pink; PDB code: 3EMM), apo NB4 (red; PDB code: 3WJB) and apo NB11 (cyan; PDB code: 4YMY).
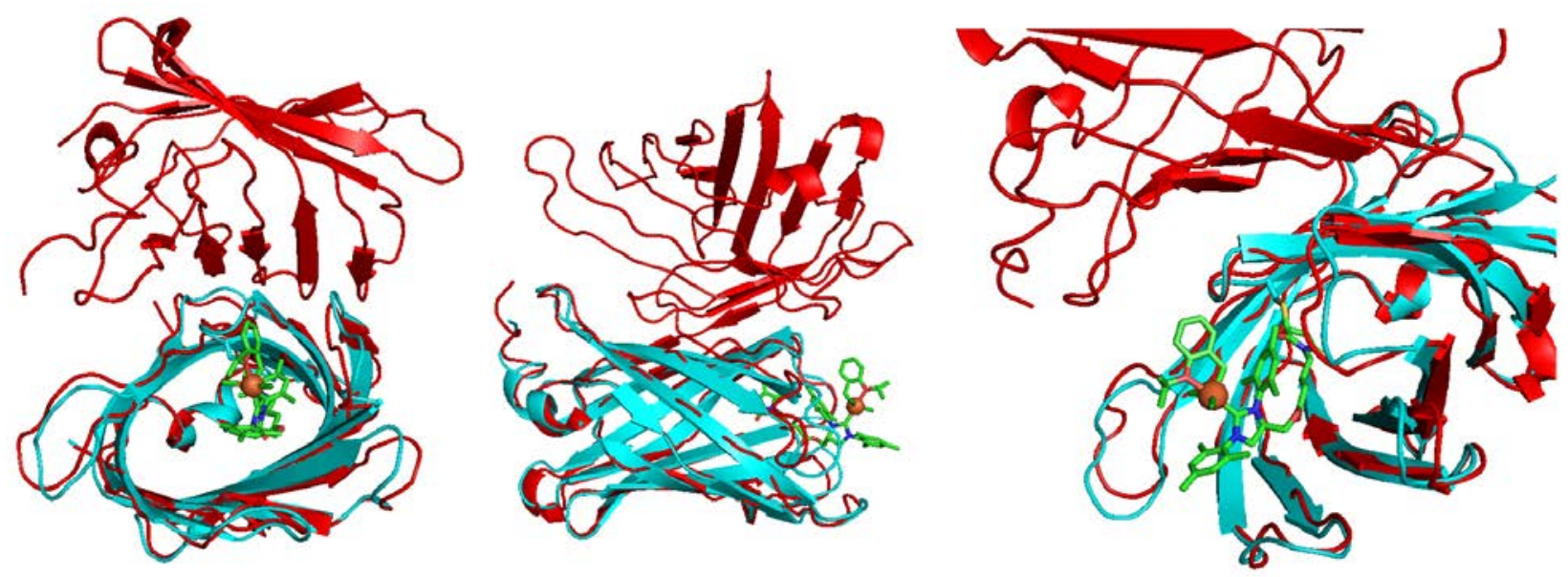

Figure S7. Overlay of calculated model structure of NB11_C3 and crystal structure of apo NB11 (PDB code 4YMY). The dimeric structure does not interfere with the active site. The figure was generated using PYMOL. ${ }^{18}$ 


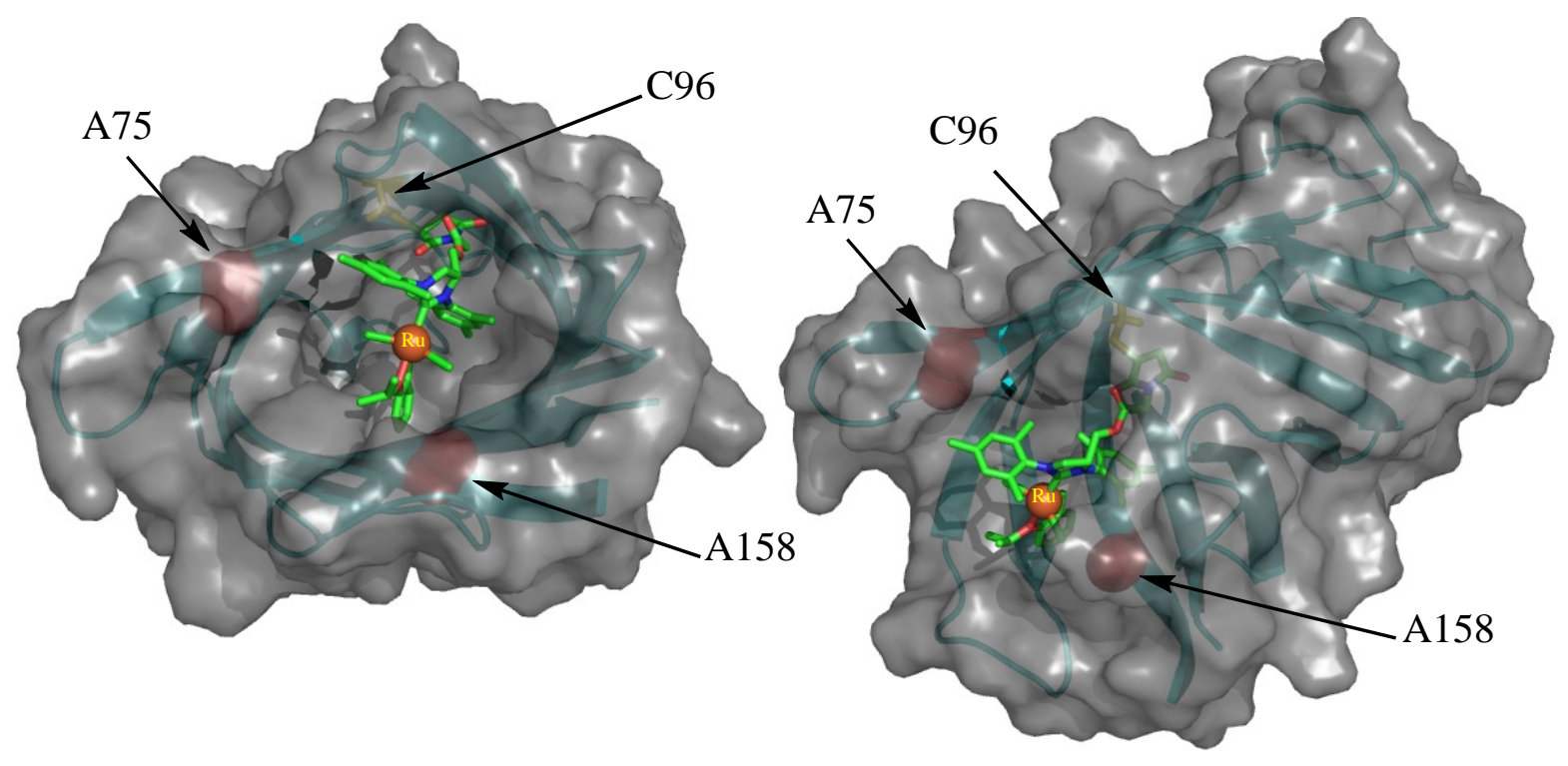

Figure S8. Model structure of NB11_C1 showing blocking of the catalyst due to deep burial of the NHC-Ligand in the cavity. The figure was generated using PYMOL. ${ }^{18}$
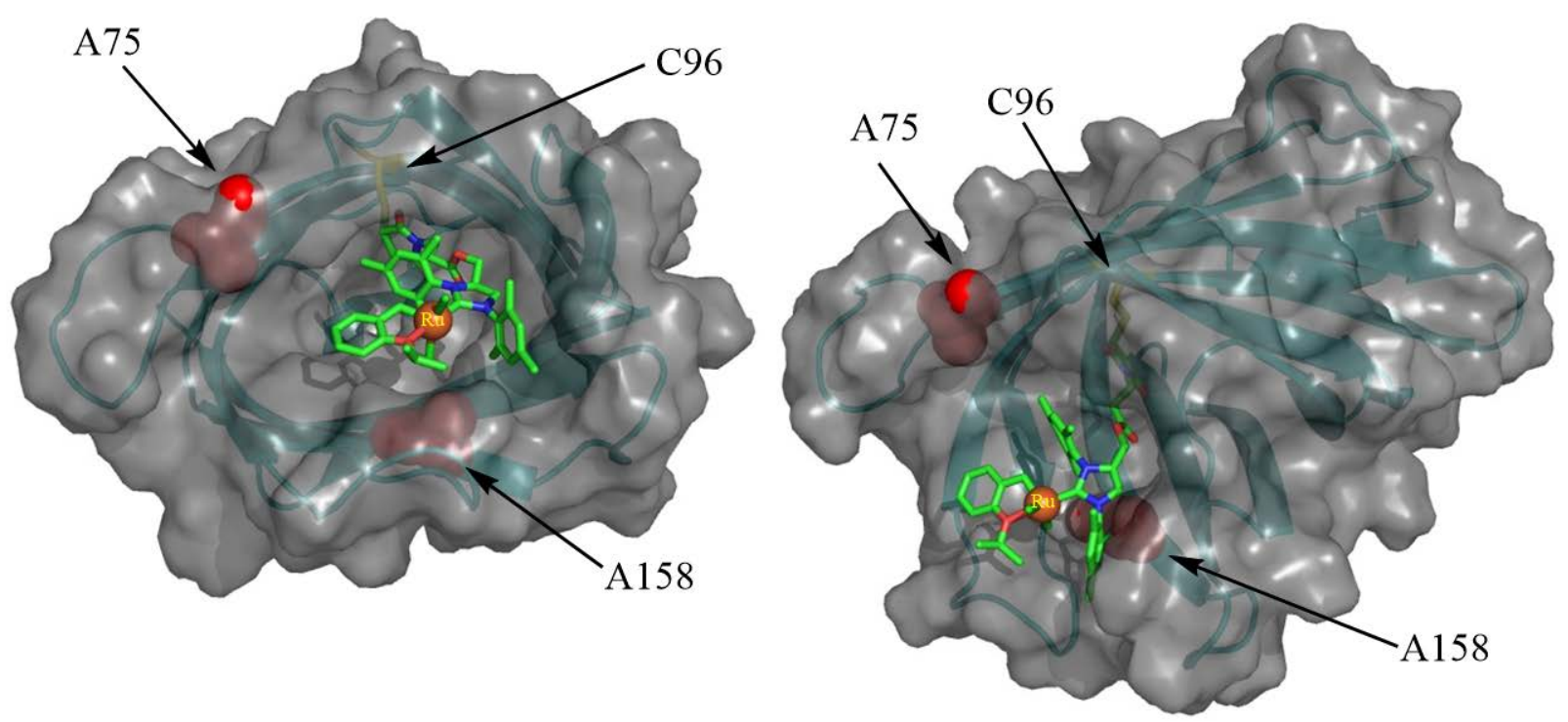

Figure S9. Model structure of NB11_C2. The figure was generated using PYMOL. ${ }^{18}$ 

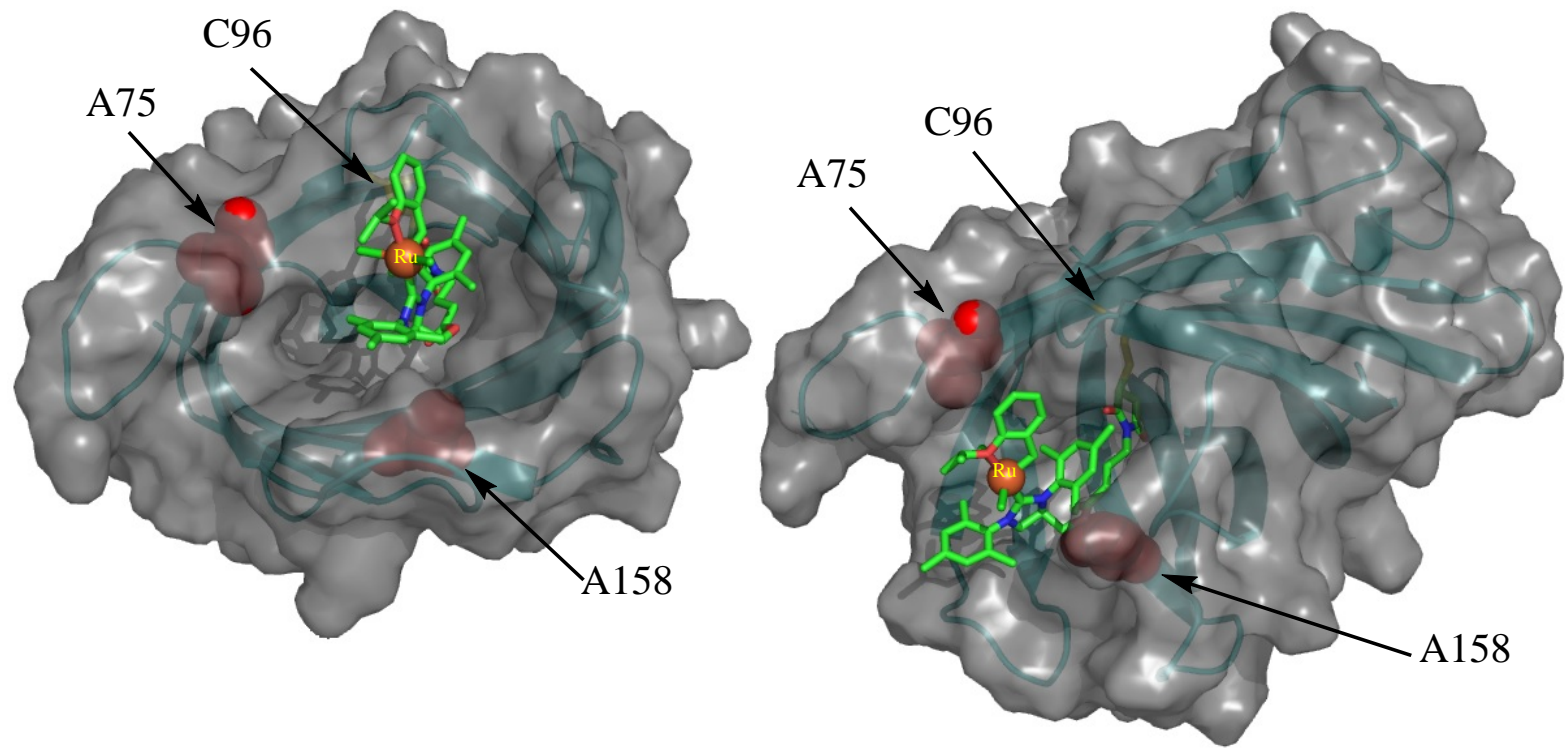

Figure S10. Model structure of NB11_C3. The figure was generated using PYMOL. ${ }^{18}$
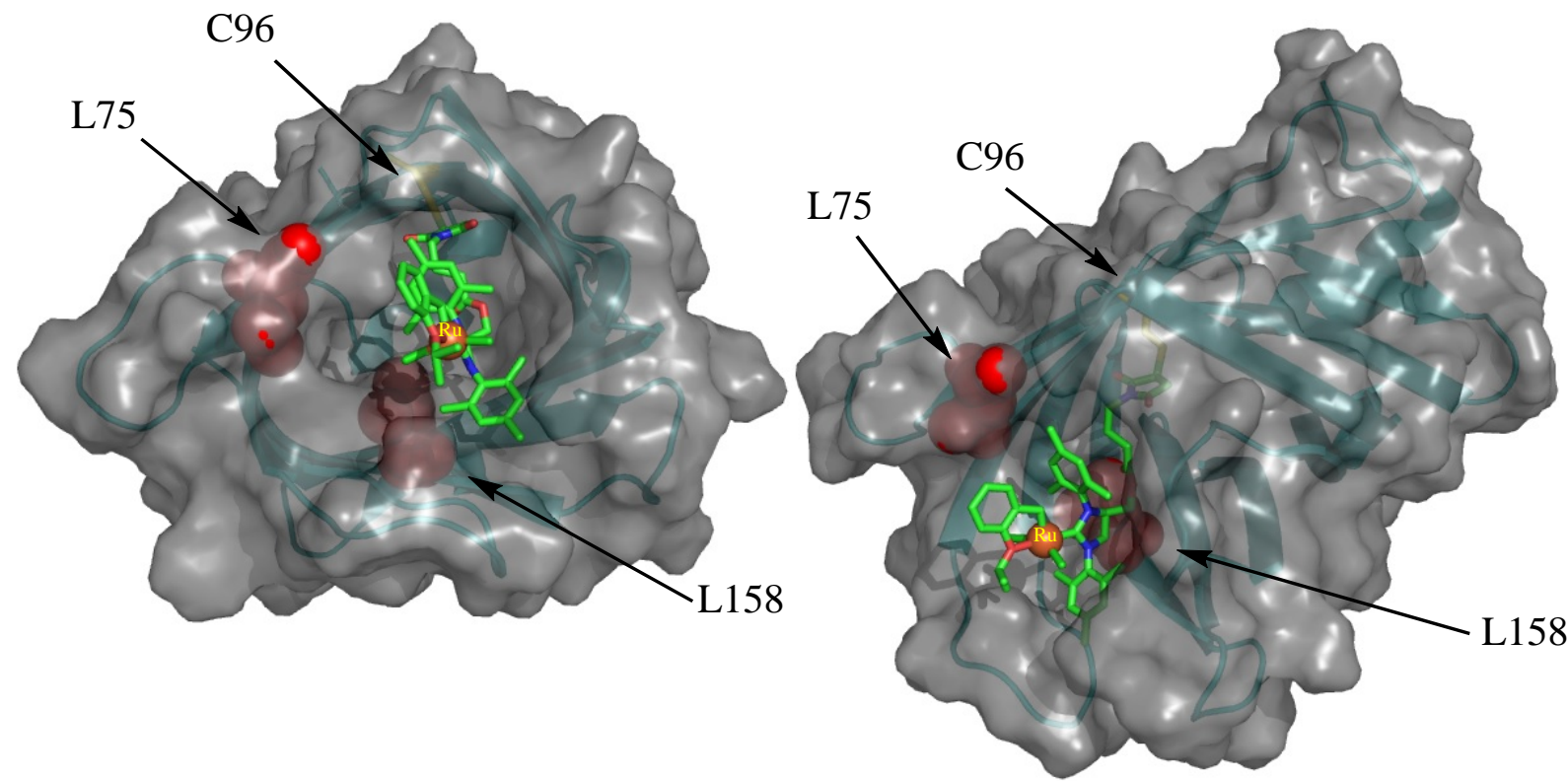

Figure S11. Model structure of NB4_C3. The figure was generated using PYMOL. ${ }^{18}$ 


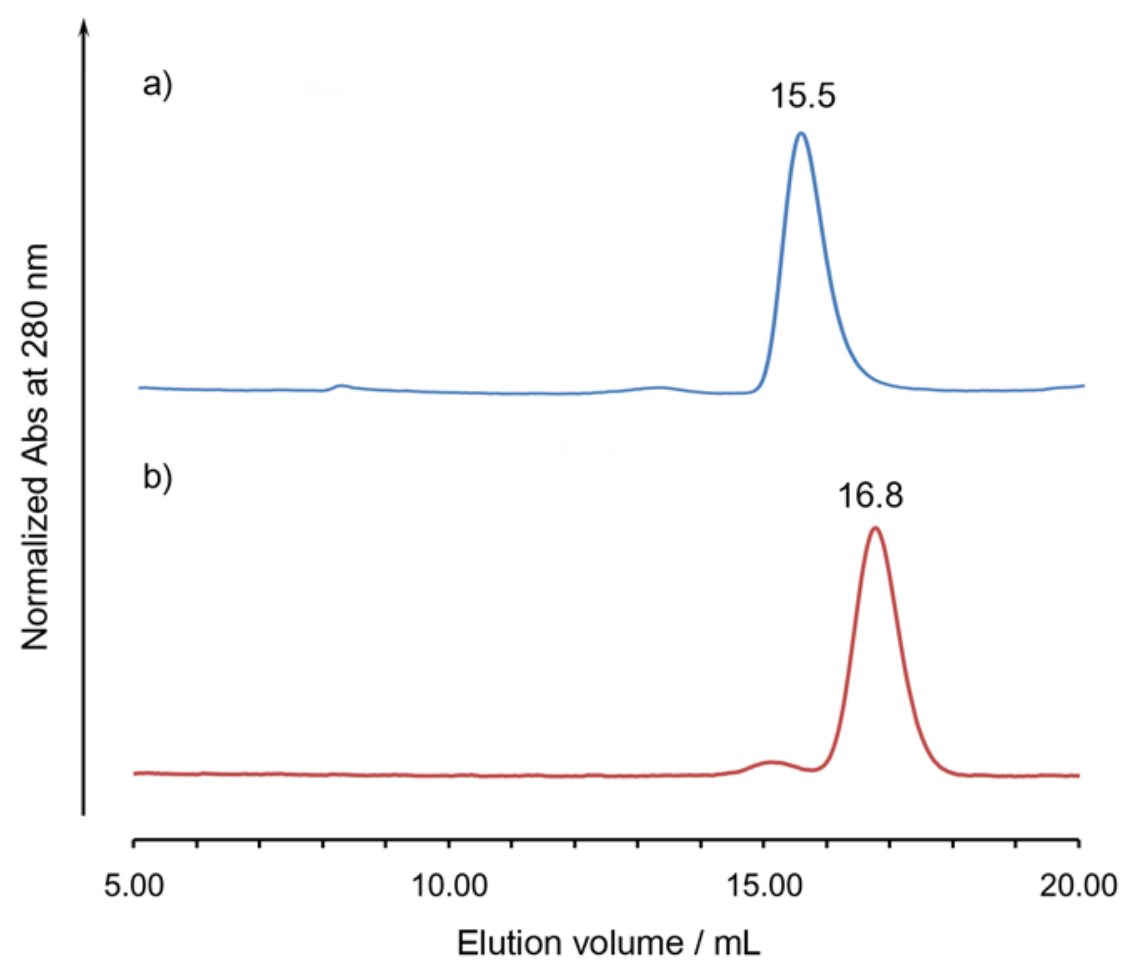

Figure S12. SEC traces of a) NB11 and b) a molecular standard (25 kDa). Eluent: $100 \mathrm{mM}$ Tris$\mathrm{HCl}$ buffer, $\mathrm{pH}$ 7.0, $200 \mathrm{mM} \mathrm{NaCl}$. 


\section{References}

(1) Philippart, F.; Arlt, M.; Gotzen, S.; Tenne, S.-J.; Bocola, M.; Chen, H.-H.; Zhu, L.; Schwaneberg, U.; Okuda, J. Chem. Eur. J. 2013, 19, 13865-13871.

(2) Sauer, D. F.; Bocola, M.; Broglia, C.; Arlt, M.; Zhu, L.; Brocker, M.; Schwaneberg, U.; Okuda, J. Chem Asian J. 2015, 10, 177-182.

(3) Feast, W. J.; Harrison, D. B. Polym. Bull. 1991, 25, 343-350.

(4) (a) Bouhadir, K. H.; Zhou, J.; Shevlin, P. B. Synth. Commun. 2005, 35, 1003-1010. (b) Adrio, L. A.; Quek, L. S.; Taylor, J. G.; Kuok Hii, K. Tetrahedron 2009, 65, 1033410338.

(5) (a) Onoda, A.; Fukumoto, K.; Arlt, M.; Bocola, M.; Schwaneberg, U.; Hayashi, T. Chem. Commun. 2012, 48, 9756-9758; (b) Fukumoto, K.; Onoda, A.; Mizohata, E.; Bocola, M.; Inoue, T.; Schwaneberg, U.; Hayashi, T. ChemCatChem 2014, 6, 12291235.

(6) Otwinowski, Z.; Minor, W. Method Enzymol. 1997, 276, 307-326.

(7) Winn, M. D.; Ballard, C. C.; Cowtan, K. D.; Dodson, E. J.; Emsley, P.; Evans, P. R.; Keegan, R. M.; Krissinel, E. B.; Leslie, A. G. W.; McCoy, A.; McNicholas, S. J.; Murshudov, G. N.; Pannu, N. S.; Potterton, E. A.; Powell, H. R.; Read, R. J.; Vagin, A.; Wilson, K. S. Acta Crystallogr. D 2011, 67, 235-242.

(8) Mccoy, A. J.; Grosse-Kunstleve, R. W.; Adams, P. D.; Winn, M. D.; Storoni, L. C.; Read, R. J. J. Appl. Crystallogr. 2007, 40, 658-674.

(9) Emsley, P.; Cowtan, K. Acta Crystallogr. D 2004, 60, 2126-2132.

(10) Murshudov, G. N.; Skubak, P.; Lebedev, A. A.; Pannu, N. S.; Steiner, R. A.; Nicholls, R. A.; Winn, M. D.; Long, F.; Vagin, A. A. Acta Crystallogr. D 2011, 67, 355-367.

(11) Krieger, E.; Darden, T.; Nabuurs, S. B.; Finkelstein, S. B.; Vriend, G. Proteins: Struct., Funct., Bioinf. 2004, 57, 678-683.

(12) Duan, Y.; Wu, C.; Chowdhury, S.; Lee, M. C.; Xiong, G.; Zhang, W.; Yang, R.; Cieplak, P.; Luo, R.; Lee, T.; Caldwell, J.; Wang, J.; Kollman, P. J. Comput. Chem. 2003, 24, 1999-2012.

(13) Wang, J.; Wolf, R. M.; Caldwell, J. W.; Kollman, P. A.; Case, D. A. J. Comput. Chem. 2004, 25, 1157-1174.

(14) Jakalian, A.; Jack, D. B.; Bayly, C. I. J. Comput. Chem. 2002, 23, 1623-1641.

(15) Garber, S. B.; Kingsbury, J. S.; Gray, B. L.; Hoveyda, A. H. J. Am. Chem. Soc. 2000, 122, 8168-8179.

(16) Sanner, M.F.; Spehner, J.C.; Olson, A.J. Biopolymers 1996, 38, 305-320.

(17) Hendlich, M.; Rippmann F.; Barnickel G. J. Mol. Graph. Model. 1997, 15, 359-63, 389.

(18) The PyMOL Molecular Graphics System, Version 1.5.0.4 Schrödinger, LLC. 